\title{
Mechanical Properties of Powder Based Steel used as Backing Plate in Heavy Duty Brake Pad Manufacturing
}

\author{
M. Asif*, K. Chandra, P.S. Misra \\ Department of Metallurgical and Materials EngineeringIndian Institute of Technology Roorkee, \\ Roorkee - 247667 (INDIA) \\ *Corresponding Author: masifiitr@gmail.com
}

\begin{abstract}
The aims of the present study is to develop a powder based steel used as backing plate for heavy duty brake pad applications. Three powder based back plate steel compositions namely B1 (C0.3, $\mathrm{Cu}$ - 1.5, P -0.3, $\mathrm{Fe}$ - 97.9), B2 (C- 0.1, $\mathrm{Cu}-2.5, \mathrm{SiC}-1, \mathrm{Fe}-96.4)$ and B3(C- 0.5, $\mathrm{Cu}-2.5$, $\mathrm{SiC}-1, \mathrm{Fe}-96.0)$ were prepared using a hot powder preform forging technique. The forged samples are of $\left(25 \times 50 \times 10 \mathrm{~mm}^{3}\right)$ dimensions. These samples were hot rolled and annealed to relieve the residual stresses. These samples were characterized in terms of microstructure, porosity content/densification, hardness and tensile properties. Densification as high near to theoretical density has been realized. Hot powder preform forging using closed die showed better densification. Rolled and annealed microstructure showed lesser porosity content than the forged one. Phosphorous causes hardening of ferrite in solid solution with iron. Compositions B1, showed reasonable elongation and it improved further on annealing. It was observed in this present investigation that, the addition, such as $\mathrm{SiC}$ and $\mathrm{Cu}$ caused increase in strength. Steel developed in the investigation are used as powder based backing plate in Manufacturing of iron based brake pads used in heavy duty applications.
\end{abstract}

Keywords: Powder based steel; brake pad manufacturing; Mechanical properties

\section{INTRODUCTION}

Powder metallurgy $(\mathrm{P} / \mathrm{M})$ processing is a net or near net shaped production technology which eradicates the need of most of the secondary operations. Automotive and highway vehicle applications dominate the ferrous $\mathrm{P} / \mathrm{M}$ structural parts market. However, there are many other fields where ferrous P/M parts are used such as lawn, garden structural parts, hand tools, hobby 
applications, and household appliances, lock hardware, industrial motors controls, hydraulic applications etc., and satisfy close dimensional tolerance requirements for parts even with complex geometries [1]. In fact any form and shape can be achieved by powder metallurgical process. It is now so established that the properties of the final part can be tailored by alloy design, impurity, process and density controls. It is increasingly becoming energy efficient and economic due to improved manufacturing technique and the ability to employ cheaper grade powders (e.g. water atomized iron powder). Despite these advantages powder metallurgical parts will continue to face stiff competition from their wrought counterparts unless it can demonstrate equivalent performance characteristics at a sustainable competitive cost. Density is by far the most important parameter in this context. As the density of powder metallurgical parts increase, physical and mechanical properties improve and at a near full density, the properties are comparable with their wrought counterparts. [2] It is apparent therefore, that a strategy for powder metallurgy substitution can only succeed if appropriate densification takes place at reasonable cost [3]. A powder based steel plate which are incorporated in manufacturing of brake pads, may be heat treated to improve toughness, economy and performance. Metal based sintered brake pads are made of three parts namely backing plate to provide tough support to brittle brake element, interface layer to facilitate joining of backing plate with brake element, and friction element to withstand frictional conditions of brake assembly. The last two were processed by powder route whereas backing plate made of wrought steel joined with friction element during pressure sintering. In spite of best efforts to join friction element, the quality of joint still remains uncertain and failures leading to separation and loss of friction element during braking application has been observed. This is a major limitation of existing technology of brake pad manufacturing where wrought steel backing plate is used. Modifications such as double sintering, hot pressing are still going on but there is neither substantial improvement in the quality nor reduction in the cost of the product owing to limited density level, higher quality of raw material requirements, and heavy investment in processing.[4]

The scope of present investigations is to develop new compositions for backing plates of iron based brake pads, so that the brake element(friction layer) is incorporated with built in powder based backing plate. Hot powder preform forged steel backing plates are expected to be highly compatible with the friction layer, because it also contains similar types of constituents.

\section{EXPERIMENTAL DETAILS}

Iron based metal matrix composites are produced by 'Hot Powder Pre form forging' technique for the use of making of steel backing plate. Rectangular samples dimensions $\left(25 \times 50 \times 10 \mathrm{~mm}^{3}\right)$ are prepared as follows: 
The raw materials (powders) chosen in the present investigation have the size ranges as given in Table 2. Three compositions namely B1, B2, and B3 are taken as given in Table1 and are prepared as per the following sequence:

(1) SiC powder is mechanically alloyed in attritor with graphite powder where the process parameters of mechanical alloying are:

Attritor speed (200rpm), Ball to charge ratio (10:1), Duration (2 hrs). This ensures coating of soft powders on hard SiC powder particles.

(2) Entire amount of iron and other powders (copper, ferro-phosphorus) as per the specified chemistry are mechanically alloyed using Attritor Mill.

(3) The entire powder mixtures (S.No 1 and S.No 2) so prepared are then mechanically mixed with each other.

(4) Requisite quantity of backing plate powder mixture is filled upto a uniform height in the die. Powder mixture pressed in a Screw forging hydraulic press with the help of upper and lower punches at a pressure $150 \mathrm{MPa}$. The compact so pressed is ejected out of the die. The die is suitably lubricated employing graphite /Zinc stearate in the suspension of methyl alcohol/ethyl alcohol for easy ejection without cracking of green compact. Then high temperature oxidation resistant glassy coating is applied on green compacts and baked at $110{ }^{\circ} \mathrm{C}$ in an oven [5]. The purpose of this coating is to protect samples from oxidation at high temperature.

(5) The coated green compacts are heated in a furnace to a temperature of $1050^{\circ} \mathrm{C}$, and held for 1 hour at this temperature.

(6) The hot powder preform are taken out from the furnace and quickly transferred into the hot die duly lubricated with graphite and fitted in the forging press. The forging is done at a speed of $500 \mathrm{~mm} / \mathrm{s}$ and a pressure of $650 \mathrm{MPa}$. The preform fully consolidates to its near theoretical density on forging. The forged component is later on ejected out of the die [6].

(7) The forged samples are subjected to high temperature resistant ceramic glassy coating again and, then annealed at a temperature of $710^{\circ} \mathrm{C}$ for 2 hours.

(8) On cooling the coating peels off by itself and residual coating if any is removed by minor surface finishing operations. 
Table 1 Chemistry of steel used as backing plate:

\begin{tabular}{|cccccc|}
\hline S.No & $\begin{array}{c}\text { Carbon } \\
\%\end{array}$ & $\begin{array}{c}\text { Copper } \\
\%\end{array}$ & $\begin{array}{c}\text { Phosphorus } \\
\%\end{array}$ & $\begin{array}{c}\text { Silicon } \\
\text { Carbide } \%\end{array}$ & $\begin{array}{c}\text { Iron } \\
\%\end{array}$ \\
\hline B1 & 0.3 & 1.5 & 0.3 & - & Balance \\
\hline B2 & 0.1 & 2.5 & - & 1 & Balance \\
\hline B3 & 0.5 & 2.5 & - & 1 & Balance \\
\hline
\end{tabular}

Table 2. Sizes of powders employed:

\begin{tabular}{|llll|}
\hline S.No. & Powder & Size range & Source \\
\hline 1 & Iron powder & $-120 \mu \mathrm{m}$ & Hoganas Industries Ltd. \\
\hline 2 & Copper powder & $-120 \mu \mathrm{m}$ & Electrolytic \\
\hline 3 & Graphite & -200 to $+150 \mu \mathrm{m}$ & Natural Crystalline Grade \\
\hline 4 & Ferro-phosphorus & $-45 \mu \mathrm{m}$ & Commercial grade \\
\hline 5 & Silicon Carbide & -180 to $+150 \mu \mathrm{m}$ & Commercial grade \\
\hline
\end{tabular}

The samples were hot rolled at $900^{\circ} \mathrm{C}$ to make thin sheets (upto $1 \mathrm{~mm}$ thickness). Rolling was carried out very slowly at $900^{\circ} \mathrm{C}$ with reduction of $0.1 \mathrm{~mm}$ thickness per pass. The sheets are then vacuum annealed at $950{ }^{\circ} \mathrm{C}$ for 2 hours to relieve the residual stresses.

Densities of the forged samples, as well as rolled and annealed sheets were determined by using Archimedes Principle for volume measurement. Forged samples as well as hot rolled and annealed sheets are subjected to metallographic examinations. This includes volume percentage of porosity and grain size measurements. The microstructures were taken at the cross-section of the as forged samples as well as rolled and annealed sheets. Cross-section for sheet in this case is along short transverse direction.

Hardness of the hot rolled and annealed sheets were measured with Vicker's hardness tester using $10 \mathrm{~kg}$ load.

For tensile testing samples were punched out from sheet as per the ASTM standard (E-32) as shown in Fig.1, and are tested using Hounsfeld tensile tester. The tensile testing was carried out at room temperature with a cross head speed $1 \mathrm{~mm} / \mathrm{min}$. 


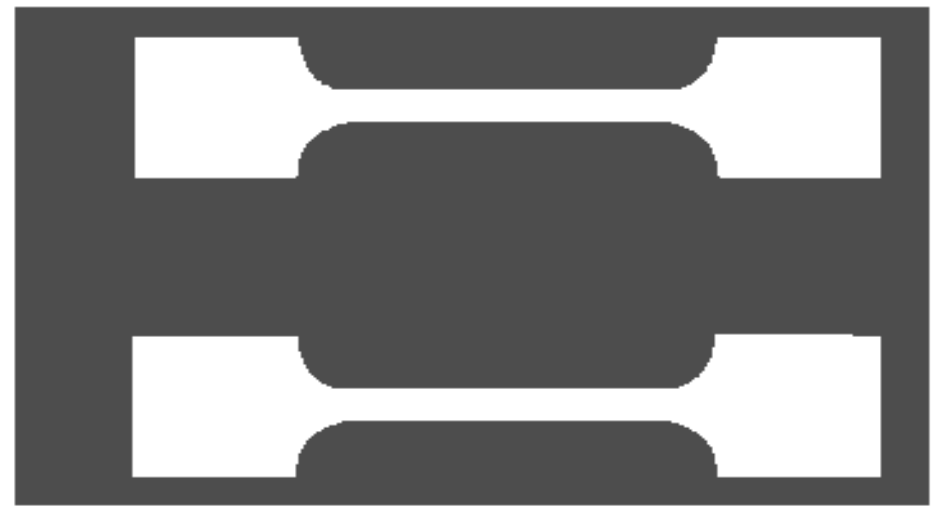

Fig.1 Rolled sheet specimen of powder forged steel having $1 \mathrm{~mm}$ thickness With tensile test specimen profiles punched out of it.

The brake elements (friction layer along with backing plate) with different backing plate compositions such as B1, B2 and B3 are formed from the powder mix of friction layer and powder mix for backing plate using 'Hot powder preform forging' technology as described in patented literature [7]. The SEM and EDAX analysis for the interface of these brake elements is shown in Fig. 4 (a-c).

\section{RESULTS AND DISCUSSIONS}

Table 3. Pore size of the powder used in compositions:

\begin{tabular}{|ll|}
\hline Sample Name & Pore diameter $(\mu \mathrm{m})$ \\
\hline B1 & $0.00268-0.621$ \\
\hline B2 & $0.00268-0.4955$ \\
\hline B3 & $0.00268-0.3735$ \\
\hline
\end{tabular}

Table 4. Mechanical properties of Steel for the use of Backing Plate:

\begin{tabular}{|l|l|l|l|l|}
\hline $\begin{array}{l}\text { Composition } \\
\text { Name }\end{array}$ & $\begin{array}{l}\text { Yield } \\
\text { stress(MPa) }\end{array}$ & UTS (MPa) & $\begin{array}{l}\text { Total elongation } \\
(\%)\end{array}$ & $\begin{array}{l}\text { Hardness } \\
(\text { Hv/10 kgf })\end{array}$ \\
\hline$(\mathrm{B} 1)$ & 126.8 & 238.5 & 11.84 & 156 \\
\hline$(\mathrm{B} 2)$ & 119.7 & 334.5 & 6.12 & 197 \\
\hline$(\mathrm{B} 3)$ & 528 & 539 & 7.04 & 175 \\
\hline
\end{tabular}




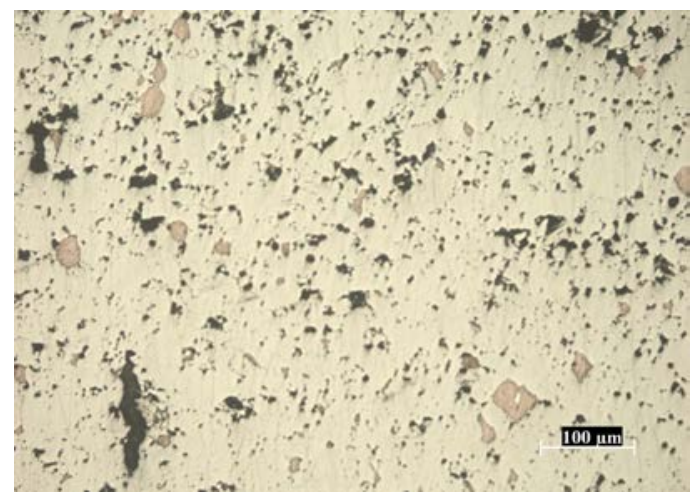

(a) B 1 (Forged)

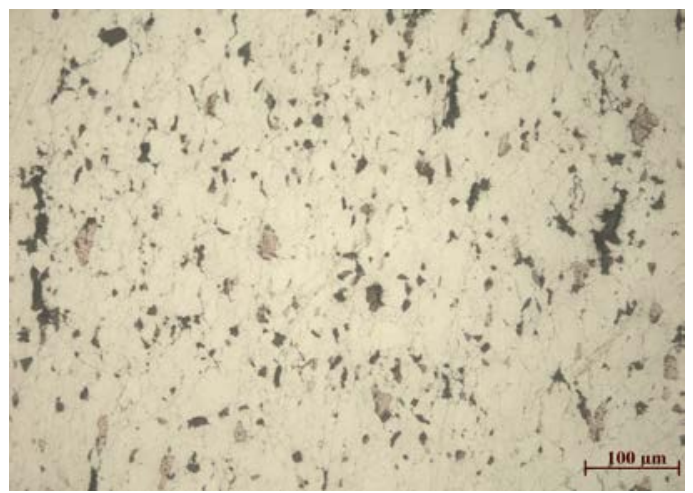

(b) B 2(Forged)

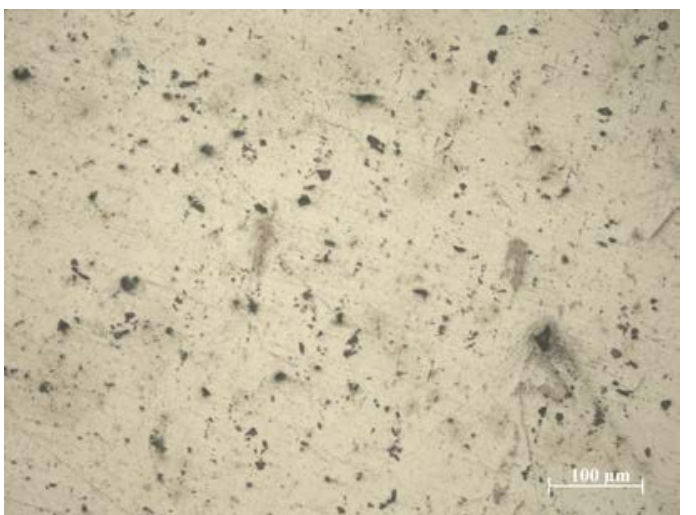

(b) B 3(Forged)

Fig. 2 (a-c) Porosity distribution of the forged and annealed sample in as polished and

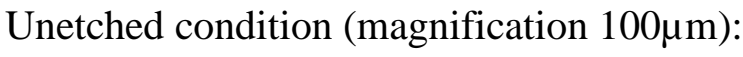

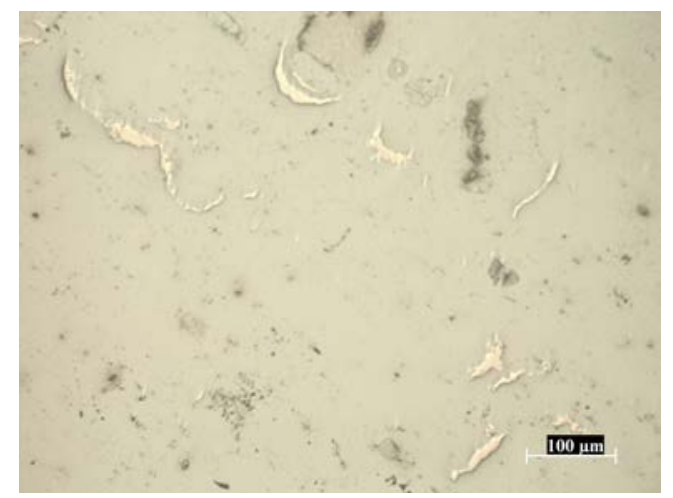

(a) B 1 (Rolled Sheet )

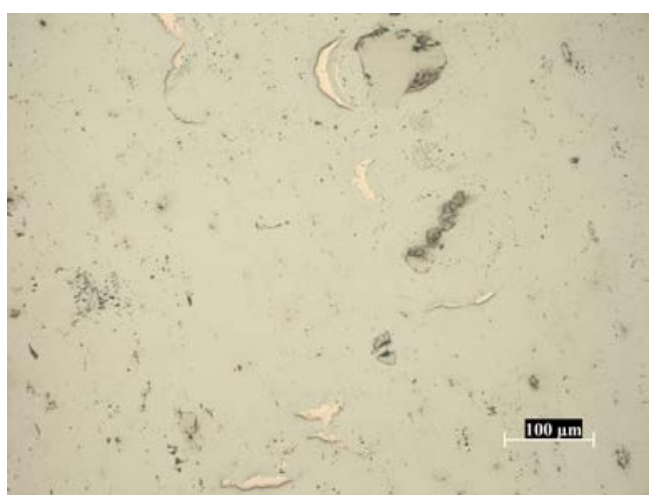

(b) B 2 (Rolled Sheet)

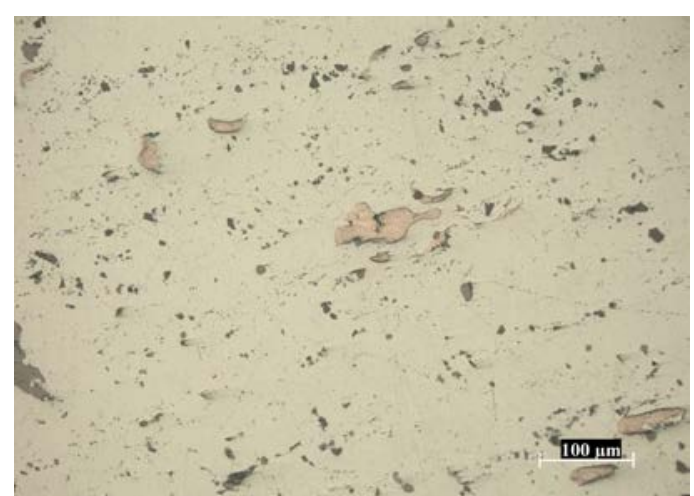

(b) B 3 (Rolled Sheet)

Fig. 3 (a-c) Porosity distribution of the Rolled and annealed sheet in as polished and Unetched condition (magnification $100 \mu \mathrm{m})$ :

Table 1 shows the chemical composition of the three samples in weight percentage. Volume percentage porosities were estimated from the measured density of the specimens. These 
estimated volume percentage of porosities are recorded in Table 5. As forged and annealed, as well as rolled and annealed microstructures were recorded and shown in Fig. 2(a-c) and Fig.3 (ac) respectively. It was found that volume percentage of porosity in grain interior is higher than grain boundaries.

Table 3 shows the pore diameter range of the samples. The microstructure of the cross section of thin sheets as shown in Fig.3 (a-c) indicates that porosities are elongated along rolling direction. Metallographic studies corresponding to B1sample show that phosphorous ions are not segregating along the grain boundaries. They get distributed uniformly in the entire structure. Tensile properties, such as yield strength, ultimate tensile strength, elongation and hardness of these (B1, B2 and B3) compositions are shown in Table 4. The backing plate corresponding to B3 composition has lower porosity in forged condition which further decreases on rolling, giving rise to higher yield strength and UTS as compared to backing plates corresponding to B1 and B2 compositions. Some of the carbon which is taken in manufacturing these B1, B2 and B3 backing plates is always oxidized during forging at high temperature and reduces the oxygen content in the backing plate samples. The coating of the green compacts with 'High temperature oxidation resistance glassy coating' protects the samples from oxidation at the surface. The higher amount of carbon content in B3 along with the presence of Silicon Carbide and Copper contributes a lot in enhancing the yield strength and ultimate tensile strength as seen for B3 backing plate composition.

Table 5. Calculated volume percentage of porosities of forged and rolled samples:

\begin{tabular}{|l|l|l|l|l|l|}
\hline Composition & $\begin{array}{l}\text { As forged } \\
\text { density } \\
\text { (g/cc) }\end{array}$ & $\begin{array}{l}\text { Rolled and } \\
\text { annealed } \\
\text { density(g/cc) }\end{array}$ & $\begin{array}{l}\text { Theoretical } \\
\text { density } \\
\text { (g/cc) }\end{array}$ & $\begin{array}{l}\text { Porosity in } \\
\text { forged } \\
\text { Sample (vol } \\
\%)\end{array}$ & $\begin{array}{l}\text { Porosity in } \\
\text { rolled and } \\
\text { annealed } \\
\text { sheets } \\
\text { (Vol \%) }\end{array}$ \\
\hline B1 & 6.3 & 6.5 & 7.8 & 23.80 & 20.1 \\
\hline B2 & 6.1 & 6.7 & 7.8 & 27.86 & 16.4 \\
\hline B3 & 6.6 & 6.9 & 7.8 & 18.18 & 13.10 \\
\hline
\end{tabular}



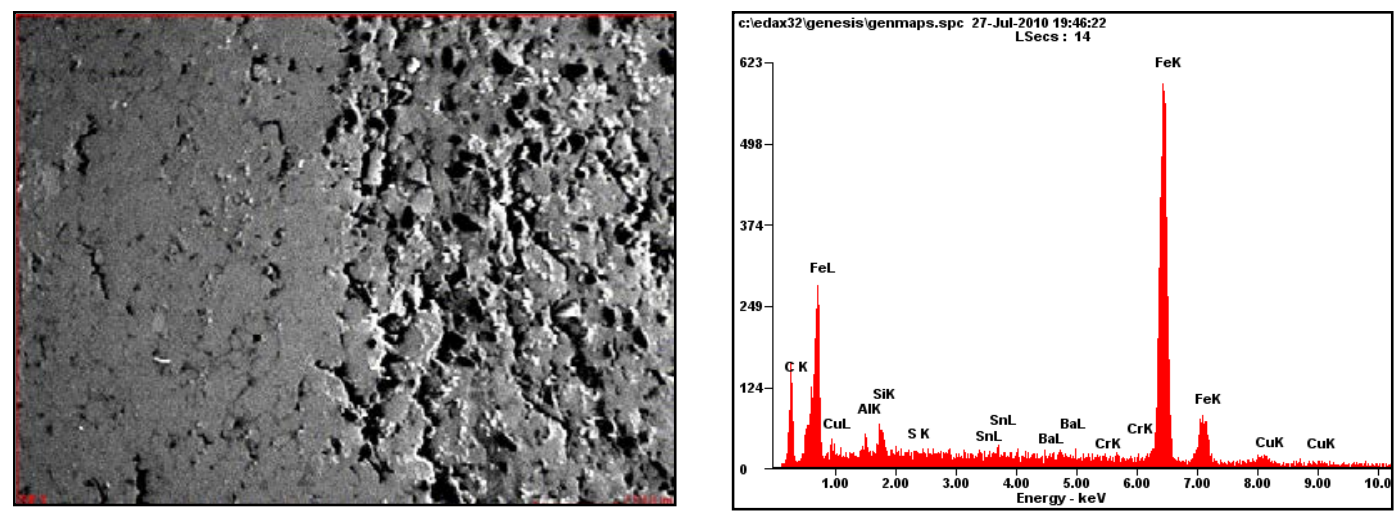

(a)
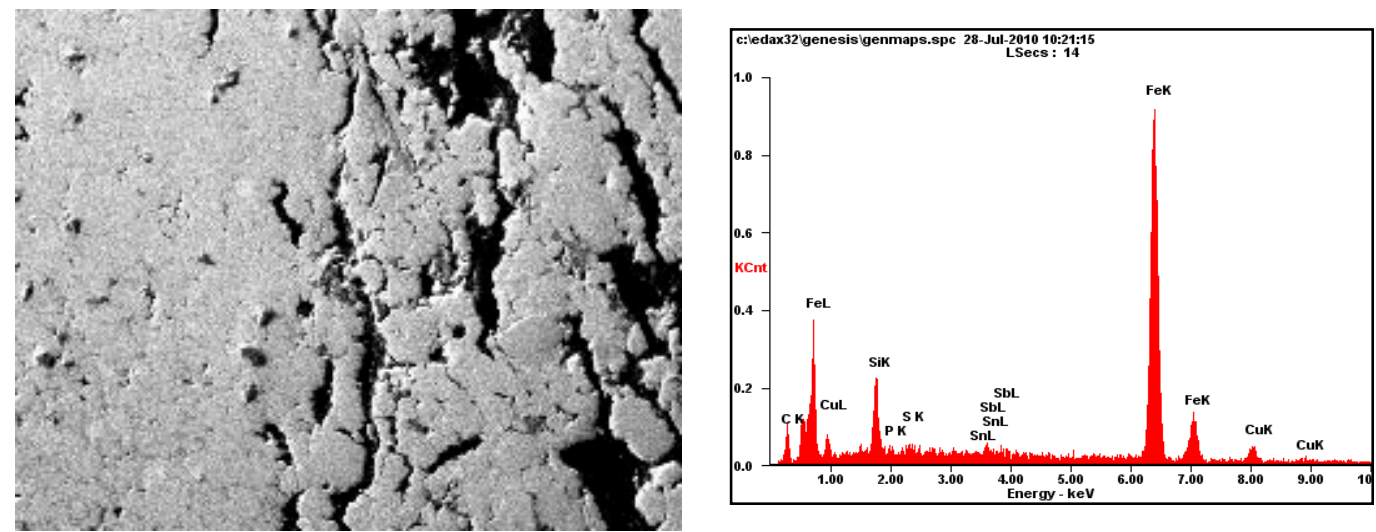

(b)
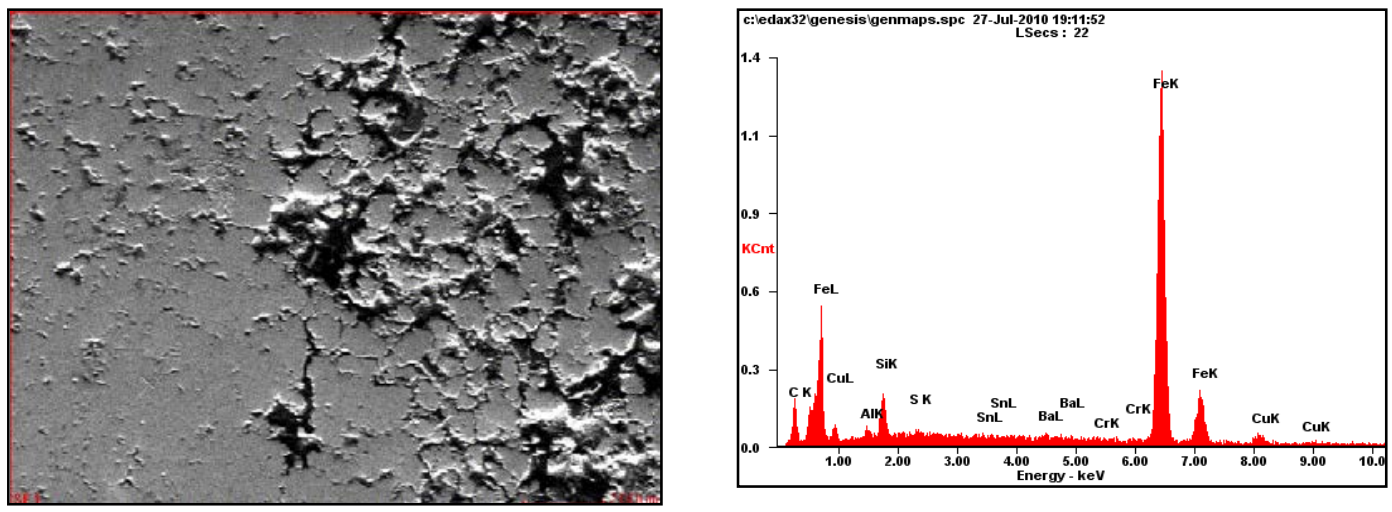

(c)

Fig.4. (a-c) Surface Morphology (SEM) and EDAX pattern for different Compositions (backing plate at left side and friction element at right side).

Fig. 4 (a-c) show the SEM and EDAX surface morphology pattern at the interface of backing plate and friction layer which indicate that i) backing plate has finer structure and has homogeneous distribution of elements; ii) there is an enhanced diffusion of carbon from friction 
element side to backing plate side (indicating the formation of strong metallurgical bond between friction layer and backing plate) and iii) there is no layered structure at the interface.

\section{CONCLUSIONS}

1. Steel developed in the present investigation have very good hot workability( As $1 \mathrm{~mm}$ thick sheets are easily deformed $10 \mathrm{~mm}$ thick forged slab by rolling, indicating about 90 $\%$ deformation).

2. Steel containing $0.5 \% \mathrm{C}$ and $1 \% \mathrm{SiC}$ showed high strength (539MPa) and high toughness under annealed conditions with the scope for developing high strength steel by cold working.

3. As forged and annealed, as well as rolled and annealed steels developed in the present investigation are characterized using metallographic techniques. All the Microstructure shows that the porosities well distributed along the grain boundaries as well as inside the grains.

4. Composition B3 shows good bonding with friction layer, as the elements are properly diffused along the interface as shown in Fig.4(c).

\section{REFERENCES}

[1] Anandakrishnan V., Sivasankaran S., Prasad K, Panday K.S., December 2009, "Influence of carbon content on workability behavior of Powder metallurgy steel”, Transaction of PMAI,Vol.35, pp26-27.

[2] Jones P., Golder K.B., Lawcock R., Shivanath R., April/May 1997, "Densification strategies for high endurance P/M components”, Int. J. Powder Metall. Vol. 33 (3), pp 37- 43.

[3] Das, J., Chandra, K., Misra, P.S., Sharma, B., 2008, "Hardness and tensile properties of FeP based alloys made through powder forging technique”. Material. Science. Engg. A, Vol. 479, pp164-170.

[4] Lenin S. D. "Development of friction materials through powder metallurgy", Ph.D.Thesis, Indian Institute of Technology Roorkee (INDIA) 2008.

[5] Misra P. S., Chandra K. "Development of High Temperature Oxidations Resistant Glassy Coating” Indian Patent, application No. 153/DEL/2010 dated Jan. 27, 2010.

[6] Asif M., Chandra K., Misra P. S., 2010, "Tribological Studies of Iron-based Brake pads made by P/M route used for Heavy Duty applications "paper Presented in International Conference organized by PMAI , PM-10 (Jan 11-13, 2010, Jaipur, India.), and published in transaction of PMAI, Vol. 36., pp78-81. 
[7] Misra P.S., Chandra K. "A process for Manufacturing Cermets Friction Materials/composites/Brake Elements With Built in Backing Plates" Indian Patent, application No. 2420/DEL/2006 dated Nov. 7 , 2006. 